\title{
IN VITRO PROPAGATION OF WADAKAHA (ACORUS CALAMUS L.)
}

\author{
A. HETTIARACHCHI, "K.K.S. FERNANDO and A.H.M. JAYASURIYA \\ Plant Genetic Resources Centre, Department of Agriculture, Gannoruwa, Peradeniya.
}

(Received: 23 September 1996; accepted: 05 September 1997)

\begin{abstract}
Wadakaha (Acorus calamus L.) is a medicinal plant of great commercial value and a potential export crop. The practice of propagating this plant based on rhizomes is inadequate to provide the planting material required for large-scale cultivation. This paper describes a tissue culture based method for mass production of Wadakaha propagules. Apical shoot meristems were cultured on MS (Murashige \& Skoog, 1962) medium supplemented with BAP or kinetin $\left(0.1-2.0 \mathrm{mgl}^{-1}\right)$ along with IAA, IBA and NAA $\left(0.01-1.0 \mathrm{mgl}^{-1}\right)$ for culture initiation. Well developed shoots were transferred to solid or liquid MS medium with BAP or kinetin (0.5-5.0 $\left.\mathrm{mgl}^{-1}\right)$ for shoot multiplication. For culture initiation the medium containing $\mathrm{BAP}\left(0.5 \mathrm{mgl}^{-1}\right)$ and $\mathrm{NAA}\left(0.2 \mathrm{mgl}^{-1}\right)$ was the best. Liquid media containing BAP $1.0 \mathrm{mgl}^{-1}$ and $2.0 \mathrm{mgl}^{-1}$ both gave the highest number of shoots ( 26 shoots/explant). The results show that BAP produced significantly more shoots than kinetin. Liquid media were more promising than solid media.
\end{abstract}

Key words: Acorus calamus, tissue culture, Wadakaha.

\section{INTRODUCTION}

Wadakaha (Sinhala); Vashambu (Tamil); Bach (Hindi) [family Araceae] is an aromatic herb of marshy habitats with a stout creeping and branching rhizome. It occurs throughout India, Sri Lanka, Philippines, temperate regions of Asia, Europe and North America, China, Japan and southern Russia. ${ }^{1}$ In Sri Lanka, the plant is cultivated as a medicinal herb. The rhizome of Wadakaha contains alkaloids, mainly choline, the bitter glucosides acorin and calamine $\mathrm{A}$, an essential oil calamol, a resin, gum, starch and tannin. The essential oil is said to contain asarone, palmitic and heptoic acids. Calamus oil is used for preparation of aromatic cordials and liquors, flavouring beer and making perfumes. In ayurveda the rhizome of this herb is used for treating diseases such as dyspepsia, flatulence, choleraic diarrhoea in children, cough, fever, piles and asthma. In the USA the rootstock is often eaten raw for relief from indigestion. The powdered rhizome is an insecticide and is used in the preparation of toilet powder. It is also an antidote for several poisons. ${ }^{2}$

Due to its varied uses, there has been a growing demand for the plant. The herb rarely produces seeds and is only propagated by vegetative means. It is not known to flower in Sri Lanka and has possibly been introduced to the country. Conventional propagation techniques are inadequate to provide the planting

\footnotetext{
Present affiliation: Regional Agricultural Research and Development Centre, Department of Agriculture, Bandarawela.
} 
material required for large scale cultivation. The present study describes an effective method for rapid multiplication of Wadakaha.

\section{METHODS AND MATERIALS}

Rhizomes of Wadakaha were collected from field-grown plants from the Matale area. They were washed thoroughly using a soap solution (Sunlight ${ }^{\mathrm{TM}}$ ) and rinsed under running tap water for about $30 \mathrm{~min}$. Then shoot-meristems of approximately $5 \mathrm{~mm}$ in length were dissected out from the rhizome and were sterilized with $70 \%$ ethanol (v/v) for $1 \mathrm{~min}$. and $20 \%(\mathrm{v} / \mathrm{v})$ commercial clorox (bleach containing $5.2 \% \mathrm{w} / \mathrm{v} \mathrm{NaOCl}$ ) with Teepol $(2-3 \mathrm{drops} / 100 \mathrm{ml}$ ) for $10 \mathrm{~min}$. followed by $0.1 \% \mathrm{HgCl}_{2}$ for $3 \mathrm{~min}$ under constant stirring. After rinsing three times with sterilized distilled water the final explants (about $2 \mathrm{~mm}$ ) were prepared by removing the outermost layers. The shoot-meristems were cultured on agar-solidified $(0.8 \% \mathrm{w} / \mathrm{v})$ MS (Murashige \& Skoog, 1962) ${ }^{3}$ medium containing either 6-benzylaminopurine (BAP) or kinetin 0.1-2.0 $\mathrm{mgl}^{-1}$ along with indoleacetic acid (IAA), indolebutyric acid (IBA) and naphthaleneacetic acid. (NAA) at a rate of $0.01-1.0 \mathrm{mgl}^{-1}$. The cultures were maintained under fluorescent light $\left(55.5 \mu \mathrm{ES}^{-1} \mathrm{~m}^{-2}, 16 \mathrm{~h}\right)$ at $26 \pm 1^{\circ} \mathrm{C}$. After $8 \mathrm{wk}$, growing shoot meristems in the medium containing $\operatorname{BAP}\left(0.5 \mathrm{mgl}^{-1}\right)$ and NAA $\left(0.2 \mathrm{mgl}^{-1}\right)$ were transferred to $20 \mathrm{ml}$ of solid or liquid MS media containing BAP or kinetin at 0.5 , $1.0,1.5,2.0,2.5,3.0,3.5,4.0,4.5$ and $5.0 \mathrm{mgl}^{-1}$ in flasks for shoot multiplication. Four replicates per treatment were used. The liquid cultures were agitated $(60 \mathrm{rpm})$ on a shaker to facilitate shoot multiplication.

Well-grown shoots were taken out from the shoot-multiplication media (shoot proliferation also occurred in the media), isolated, and cultured on MS solid medium without any growth regulators for root induction. Subsequently the rooted plantlets were transferred to a soil mixture in pots ( $5 \mathrm{~cm}$ diameter) of sand: top soil: compost 1:1:1 and maintained in the glasshouse for $2-3 \mathrm{wk}$. Finally the plantlets were established in the field.

Data analysis: Analysis of variance was done using MINITAB data analysis software package for a three factorial randomized complete block design and treatments were compared using least significant values.

\section{RESULTS}

Cultures were established in the MS media containing BAP or kinetin (0.5 - 1.0 $\left.\mathrm{mgl}^{-1}\right)$ along with IAA, IBA and NAA (0.01- $\left.0.5 \mathrm{mgl}^{-1}\right)$ within 8-10 wk of culture. Of these culture media, the medium supplemented with $\operatorname{BAP}\left(0.5 \mathrm{mgl}^{-1}\right)$ and NAA $\left(0.2 \mathrm{mgl}^{-1}\right)$ produced what appeared to be the most vigorous shoots. However, IAA, IBA or NAA at higher levels (over $0.5 \mathrm{mgl}^{-1}$ ) induced calli at the base of the shoot-meristems, suppressing shoot growth. When cytokinin (BAP, 
kinetin) levels were above $1.0 \mathrm{mgl}^{-1}$, shoot elongation was less, and callus formation was observed at the base of the shoot-meristems.

When single shoots taken from the culture medium with $\mathrm{BAP}\left(0.5 \mathrm{mgl}^{-1}\right)$ and NAA $\left(0.2 \mathrm{mgl}^{-1}\right)$ were transferred to shoot-multiplication media (solid and liquid), shoot proliferation [Fig. 2(a)] through bud formation occurred within 8 wk of transfer. The results are shown in Fig. 1.

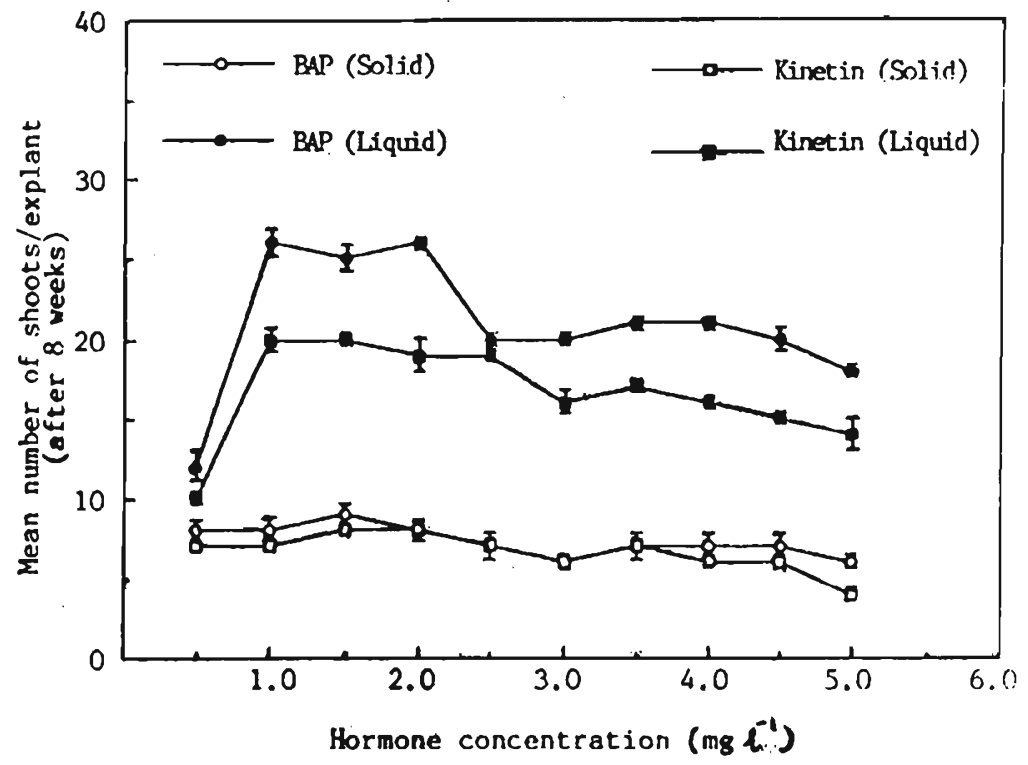

Figure 1: Effect of BAP and Kinetin on shoot proliferation in solid and liquid media.

These results show that the mean number of shoots that formed on solid media was $7.0 \pm 0.2$ per explant. Shoot multiplication was significantly enhanced (19.0 \pm 0.5 mean number of shoots/explant) in liquid cultures (Table 2). Also the results show that BAP was significantly more effective than kinetin for shoot-proliferation (Table 1). At higher levels $\left(>2.0 \mathrm{mgl}^{-1}\right)$, particularly $\mathrm{BAP}$ in liquid media inhibit shoot proliferation.

When cytokinin (BAP, kinetin) levels were above $2.0 \mathrm{mgl}^{-1}$, calli formed at the base of the newly formed shoots, both in the solid and the liquid media. When the cytokinin levels were increased further (above $4.0 \mathrm{mgl}^{-1}$ ) these shoots did not show elongation.

When these single shoots were isolated and transferred to root induction medium of MS without any growth regulators, within 4-5 wk of culture, 6-8 roots were visible. When these plantlets were established in soil [Fig. 2(b)] the survival rate was approximately $75 \%$. 
Table 1: Analysis of variance on the effect of hormones (BAP \& kinetin) on shoot proliferation of Wadakaha.

\begin{tabular}{lcrrrr}
\hline $\begin{array}{l}\text { Source of } \\
\text { variation }\end{array}$ & df & ss & ms & F \\
\hline Between groups & 1 & 250.0000 & 250.0000 & $5.6782^{*}$ \\
Within groups & 158 & 6956.4000 & 44.0278 & \\
\hline
\end{tabular}

$\mathrm{df}=$ degrees of freedom; ss $=$ sums of squares; $\mathrm{ms}=$ mean square; $\mathrm{f}=\mathrm{F}$ value; ${ }^{*}=\mathrm{p}<0.05$

Table 2: Analysis of variance on the effect of status (solid or liquid) of media on shoot proliferation.

\begin{tabular}{lrrrr}
\hline $\begin{array}{l}\text { Source of } \\
\text { variation }\end{array}$ & $\mathrm{df}$ & ss & $\mathrm{ms}$ & $\mathrm{F}$ \\
\hline Between groups & 1 & 5569.6000 & 5569.6000 & $537.6327^{* * *}$ \\
Within groups & 158 & 1636.8000 & 10.3959 & \\
\hline
\end{tabular}

$\mathrm{df}=$ degrees of freedom; ss $=$ sums of squares; $\mathrm{ms}=$ mean square; $\mathrm{f}=\mathrm{F}$ value; $* * * \mathrm{p}<0.01$

\section{DISCUSSION}

An initial problem encountered was the elimination of microorganisms from the explants as they were taken from rhizomes growing in soil. However, the problem could be overcome when the rhizomes were washed thoroughly using a soap solution (Sunlight ${ }^{\mathrm{TM}}$ ) and rinsed under running tap water for about $30 \mathrm{~min}$ followed by chemical sterilization. Although $\mathrm{HgCl}_{2}$ is highly toxic and its use for sterilization is not recommended, it was found that out of the chemicals used in the present study soil microorganisms could be eliminated only by the use of $\mathrm{HgCl}_{2}$. The sterilization procedure adopted in this study gave about $85-90 \%$ survival. The contaminants were mostly fungal and rarely bacterial. The developed methodology has also been successful in the elimination of microorganisms from explants of ginger which also harbour soil microorganisms. ${ }^{4}$ Thus this method could be utilized for explants taken from soil. 

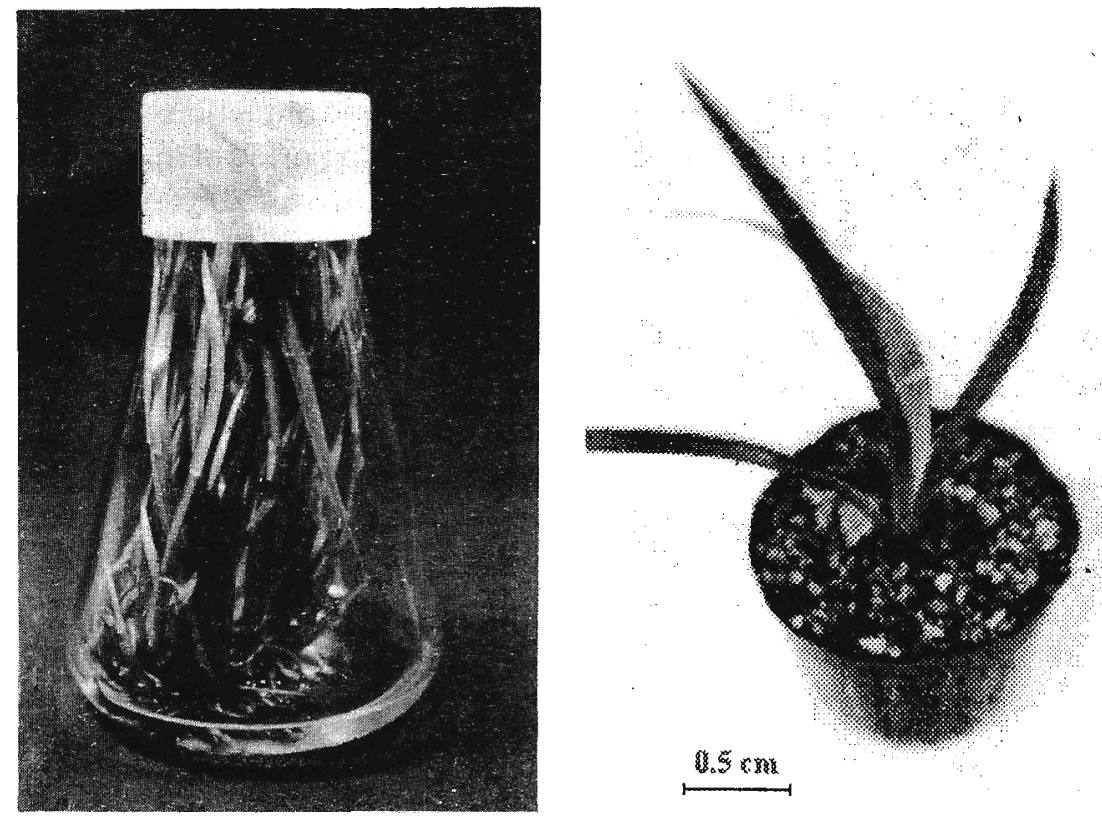

Figure 2: In vitro culture of Acorus calamus L. (Wadakaha).

(a) Shoot multiplication

(b) In vitro derived plant after transferring to soil

Though the results indicate that cultures could he established with BAP or kinetin (0.5-1.0 $\left.\mathrm{mgl}^{-1}\right)$ along with IAA, IBA or NAA $\left(0.01-0.5 \mathrm{mgl}^{-1}\right)$, the combination BAP and NAA was most favourable for culture establishment. Also the results indicate that for shoot multiplication, liquid media were more effective than the same media solidified with agar. Similar results have been reported for shoot multiplication in Gloriosa superba. ${ }^{5}$ The present results show that in the proliferation phase, when the cytokinin level was above $2.0 \mathrm{mgl}^{-1}$, callus formation occurred both in the solidified and liquid media. Hence, it is not advisable to use cytokinin over $2.0 \mathrm{mgl}^{-1}$ for shoot multiplication of these plants, as the formation of callus can induce genetic variation. ${ }^{6}$ In liquid cultures both kinetin and BAP enhanced shoot multiplication, but BAP was more effective than kinetin. BAP concentrations of $1.0 \mathrm{mgl}^{-1}$ and $2.0 \mathrm{mgl}^{-1}$ gave the highest amount of shoot proliferation (mean number of shoots/explant 26). Since there was no difference between them, BAP at $1.0 \mathrm{mgl}^{-1}$ was selected as the optimum concentration for the proliferation phase. Almost similar results have been reported for shoot multiplication in ginger. ${ }^{4}$

In this study MS medium without any growth regulators performed well for root induction. Therefore the authors did not examine the effectiveness of any other growth regulators for root induction. Earlier studies with komarika 
indicated that root formation could easily be induced in similar media without much difficulty. ${ }^{7}$

It is interesting to note that the medium used for root induction of Wadakaha could also be used to conserve the in vitro cultures for a period of approximately one year without subculturing at a reduced temperature of $20^{\circ} \mathrm{C}$ (unpublished data). Therefore the established method can be used to conserve this plant in the in vitro collection. If materials like sorbitol or mannitol are added and at further reduced temperatures the conservation period ( $11 / 2$ years) is said to be prolonged. ${ }^{8}$

Establishment of in vitro grown plantlets in soil is one of the major difficulties encountered in a micropropagation procedure. The plantlet survival rate on transfer to soil is reported to be extremely low in woody plants. ${ }^{9}$ The present study showed the survival rate of Wadakaha was about $75 \%$ which is satisfactory. In conclusion, the results suggest that in vitro culture of Wadakaha, a useful technique for rapid multiplication, is feasible.

\section{Acknowledgement}

The authors are indebted to Prof. M.D. Dassanayake \& Dr. P.K. Samarajeewa for valuable suggestions, support and encouragement and H.M.S. Wijayaratne, U. Siriyadasa and R. Gunatunge for their co-operation in preparing the manuscript.

\section{References}

1. Nicolson D.H. (1987). Araceae. In: A Revised handbook to the flora of Ceylon (Eds. M.D. Dassanayake and F.R.Fosberg) 6: 28. AMERIND, New Delhi.

2. Jayaweera D.M.A. (1982). Medicinal plants used in Ceylon, Part 1. pp. 120 121. National Science Council, Colombo.

3. Murashige T. \& Skoog F. (1962). A revised medium for rapid growth and bioassay with tobacco cultures. Physiologia Plantarum 15: 473-497.

4. Hettiarachchi A. \& Fernando K.K.S. (1995). Mass propagation of ginger through tissue culture. Proceedings of the Sri Lanka Association for the Advancement of Science, Part 1. (Abstract) p. 128.

5. Samarajeewa P.K., Dassanayake M.D. \& Jayawardena S.D.G. (1993). Clonal propagation of Gloriosa superba L. Indian Journal of Experimental Biology 31: 719-720. 
6. Trever A. \& Thorpe. (1981). Plant tissue culture and application in agriculture. Academic Press, London. pp. 45-88.

7. Hettiarachchi A., Mendis M.H., Rajapakse D.P., Ganashan P. \& Jayawardena S.D.G. (1992). In vitro propagation of Komarika (Aloe vera (L.) Burm. f.). Proceedings of the Sri Lanka Association for the Advancement of Science, Part 1. (Abstract) p. 37.

8. Zamora A.B., Paet C.N. \& Altoveros E.C. (1994). Micropropagation and virus elimination procedures in potato for conservation, dissemination and production in the humid tropics. pp. 29-32. Academic Press, London.

9. Abeyratne W.H., Bandara D.C. \& Senanayake Y.D.A. (1991). In vitro propagation of Nadun (Pericopsis mooniana) through callus culture. Tropical Agricultural Research 3: 242-252. 